\title{
Tarifa Efetiva de Proteção Alfandegária
}

Interessante notar que os recentes debates, documentos oficiais, comentários por especialistas ou não do Brasil, a respeito da exportação de produtos manufaturados ou semimanufaturados brasileiros para os países desenvolvidos têm deixado de mencionar um relevante aspecto dêste assunto. Trata-se da diferença existente entre a tarifa alfandegária nominal e a tarifa efetiva. No entanto, muitos economistas de outros países, principalmente os que trabalharam na II Conferência das Nações Unidas sôbre Desenvolvimento e Comércio (UNCTAD, Nova Deli, 1968) consideram a tarifa efetiva o mais importante nôvo conceito dos últimos anos no campo de teoria econômica internacional.

Com referência ao estabelecimento de um regime de tarifas preferenciais para a importação de produtos manufaturados e semimanufaturados dos países em desenvolvimento, é preciso assinalar o seguinte: o importante para o comércio não são as tarifas alfandegárias incidentes sôbre as mercadorias, mas sim as tarifas efetivas de proteção ao valor adicionado implícito na estrutura tarifária. Estas tarifas efetivas tendem a ser altas sôbre as exportações reais e potenciais dos países subdesenvolvidos. A progressão de tarifas por estágio de produção faz com que as tarifas efetivas de proteção sejam maiores do que as tarifas nominais para bens com maiores graus de industriali-

R. Adm. Emp., Rio de Janeiro, 9 (3): 119-126, jul./set. 1969 
zação. As tarifas nominais em bens de interêsse para os países menos desenvolvidos tendem a ser excepcionalmente altas. ${ }^{1}$

Note-se, a êsse respeito, os resultados de um estudo em que o economista Bela Balassa estima para diversos países, as médias de tarifas efetivas e as compara com as médias de tarifas nominais (estas últimas são aqui colocadas entre parênteses); EUA 20.0 (11.6); Reino Unido 27.8 (15.5); MCE 18.6 (11.9); Suécia 12.5 (6.8); Japão 29.5 (16.2). As tarifas efetivas sôbre o valor adicionado em processos industriais de especial interêsse para os países subdesenvolvidos variam principalmente ao redor de $35 \%$ nos países acima citados. ${ }^{2}$

Define-se tarifa efetiva de proteção considerando-se constante a taxa cambial, como o aumento percentual ao valor adicionado, por unidade, num processo industrial que se realiza em razão de uma estrutura tarifária - em relação ao que ocorreria na ausência de tarifas. ${ }^{3}$

A fórmula da tarifa efetiva, ao supormos imobilidade internacional de fatôres de produção, indica o grau de proteção ao valor adicionado no processo industrial. Se os coeficientes de insumo forem considerados constantes dentro de níveis relevantes de produção, a tarifa efetiva de proteção a qualquer mercadoria pode ser expressa no contexto de um sistema de insumo-produto.

Suponhamos que a tarifa aduaneira para tecidos de algodão no Mercado Comum Europeu seja de $20 \%$, que a tarifa aduaneira sôbre o algodão seja zero, e que o valor do algodão seja $50 \%$ do valor do produto final, o tecido. Como o algodão é livre de direitos e pode ser importado pelos produtores de tecidos, a tarifa sôbre o tecido aplica-se meramente ao valor adicionado pelo industrial, isto é, à metade do valor total, e não ao preço de venda do tecido de algodão. A tarifa nominal de $20 \%$ sôbre o valor total é, na verdade, uma tarifa efetiva de $40 \%$ sôbre o valor adicionado. ${ }^{4}$

1 Vide Johnson, Harry G. Economic Policies Toward Less Developed Countries, p. 96 a 104, publicado em 1967 pelo Brookings Institution (F. A. Praeger, Editôres).

2 Vide Balassa, Bela. Tariff Protection in Industrial Countries: An Avaluation, Journal of Political Economy, vol. 73, dezembro de 1965, p. 94 e 573.

3 Vide Conden, W. M. The Structure of the Tariff..., Part I, Joumal of Political Economy, junho de 1966.

4 Vide Kindleberger, Charles P. International Economics, Richard D. Irwin Inc., $4 .^{2}$ edição, 1968, p. 110 e 111. 
A fórmula para a tarifa efetiva é: $\mathbf{f}=\frac{t-q r}{1-r}$ onde

f = tarifa efetiva sôbre o bem final, o tecido de algodão.

$\mathfrak{t}=$ tarifa nominal sôbre o bem final, o tecido de algodão.

$q=$ tarifa sôbre componentes ou bens intermediários, a matéria-prima algodão.

$\mathbf{r}=$ proporção do bem final, representada pelos componentes ou bens intermediários importados.

Quando os componentes são livres de direitos, a fórmula se reduz a:

$$
f=\frac{t}{1-r}
$$

No exemplo acima, do tecido de algodão, teríamos:

$$
f=\frac{0,20}{1-0,50}=0,40
$$

Se houvesse um aumento na tarifa aduaneira, sôbre o algodão, de zero para $5 \%$, teríamos

$$
f=\frac{t-q r}{1-r}=\frac{0,20-0,05 \cdot 0,50}{1-0,50}=\frac{0,175}{0,50}=0,35
$$

Portanto, um aumento na tarifa aduaneira sôbre a matéria-prima algodão irá diminuir a tarifa efetiva de proteção ao produtor de tecidos de algodão.

Se a taxa aduaneira fôr a mesma, tanto para o produto final como para os componentes ou o insumo, isto é, $q=t$, então a tarifa nominal será igual à tarifa efetiva, isto é, $t=f$.

Pode-se então verificar a importância da diferença entre tarifa nominal e tarifa efetiva, nos países desenvolvidos, para todos aquêles que, 
como brasileiros, gostariam de passar a exportar relativamente muito mais café solúvel do que café ém grãos, muito mais tecidos do que algodão, muito mais chocolate do que cacau, muito mais óleo de mamona do que mamona, muito mais aço do que minério de ferro, muito mais veículos do que aço, e assim por diante. Vale acrescentar que diversos economistas americanos, como HARRY G. JoHNSON, da Universidade de Chicago, em seu livro Economic Policies Toward Less Developed Countries, já vêm procurando averiguar, com base em dados empíricos, quais seriam as conseqüências e preferências tarifárias nos Estados Unidos para os países menos desenvolvidos, levando-se em conta as tarifas efetivas. ${ }^{\check{c}}$ e 8

\section{UM EXEMPLO NUMERICO}

Vamos supor:

a) um certo produto final, $\mathrm{j}$, com preço igual a $\mathbf{P j}_{\mathbf{1}}=\$ 1,00$

b) os materiais, $i$, utilizados como insumo, com preço no mercado mundial igual a $\mathbf{P i}_{1}=\$ 0,50$

c) tarifa nominal sôbre o produto final $\mathrm{t}=10 \%$

d) tarifa nominal sôbre a matéria-prima $q=10 \%$

A tarifa efetiva que irá proteger os produtores nacionais será:

$$
f=\frac{t-q r}{1-r}
$$

onde $\mathrm{r}=$ coeficiente de insumo-produto.

5 Vide também estudo de BeLA Balassa, da John Hopkins University, no qual êle assinala que do ponto de vista do empreendedor, no país subdesenvolvido, ao decidir transformar uma matéria-prima em produto semi-acabado ou produto acabado para exportação aos países desenvolvidos, a tarifa relevante é aquela que pesa sôbre o valor adicionado no processo de produção ao invés da tarifa aduaneira nominal. Trade Prospects for Developing Countries, Homewood, Ill.: R. D. Irwin Inc., 1964, p. 116.

6 Vide Johnson, Harry G. Tariffs and Economics Development: Some Theoretical Issues, Journal of Development Studies, outubro de 1964. 
O coeficiente de insumo-produto é:

$$
\mathbf{r}=\frac{\mathrm{Pi}_{1}}{\mathrm{Pj}_{1}}=\frac{0,50}{1,00}=0,50
$$

Temos,

$$
\mathrm{f}=\frac{0,10-(0,10 \times 0,50)}{0,50}=\frac{0,10-0,05}{0,50}=0,10=10 \%
$$

O valor da tarifa efetiva também poderia ser obtido da seguinte forma:

Preço no mercadó mundial de $\mathrm{j}: \mathrm{Pj}_{1}=\$ 1,00$.

Preço no mercado mundial de $\mathrm{i}: \mathbf{P i}_{1}=\$ 0,50$

Valor adicionado no país no caso de não existir tarifa alguma:

$$
\mathrm{Vj}_{1}=\mathrm{Pj}_{1}-\mathrm{Pi}=1,00-0,50=0,50
$$

Preço de j no país no caso de existir $10 \%$ de tarifa:

$$
\mathrm{Pj}_{2}=\$ 1,10
$$

Preço de i no país no caso de existir $10 \%$ de tarifa:

$$
\mathrm{Pi}_{22}=0,55
$$

Valor adicionado no país no caso de haver tais tarifas:

$$
\mathrm{Vj}_{2}=\mathrm{Pj}_{2}-\mathrm{Pi}_{2}=1,10-0,55=0,55
$$

Pela definição da tarifa efetiva ela será igual a:

$$
f=\frac{V j_{2}-V j_{1}}{V j_{1}}=\frac{0,55-0,50}{0,50}=\frac{0,05}{0,50}=0,10=10 \%
$$

Vamos supor agora que seja dada uma preferência de $100 \%$ a alguns produtores estrangeiros. Assim a tarifa nominal sôbre o produto final torna-se nula, $\mathrm{t}=\mathrm{O}$, e a tarifa sôbre os materiais continua $\mathrm{a}$ mesma, $\mathrm{q}=10 \%$. 
A tarifa efetiva torna-se então

$$
f=\frac{t-q r}{1-r}=\frac{O-(0,10 \times 0,50)}{0,50}=\frac{-0,05}{0,50}=-0,10=-10 \%
$$

ou pela fórmula alternativa,

$$
\begin{aligned}
& \mathrm{Pj}_{1}=\$ 1,00 \quad \mathrm{Pj}_{2}=\$ 1,00 \\
& \mathbf{P i}_{1}=\$ 0,50 \quad \mathbf{P i}_{2}=\$ 0,55 \\
& \mathrm{Vj}_{1}=1,00-0,50=0,50 \quad \mathrm{Vj}_{2}=1,00-0,55=0,45 \\
& \mathbf{f}=\frac{\mathrm{Vj}_{2}-\mathrm{Vj}_{1}}{\mathrm{Vj}_{1}}=\frac{0,45-0,50}{0,50}=\frac{-0,05}{0,50}=:-10 \%
\end{aligned}
$$

Uma tarifa negativa de proteção alfandegária, $-10 \%$, será assim imposta aos produtores nacionais.

\section{ILUSTRAÇÃo DA IMPORTANCLA DE PREFERENCIAS TARIFARIAS}

Vamos mostrar a razão pela qual as preferências tarifárias em mercados de países desenvolvidos para exportações de produtos manufaturados e semimanufaturados de países subdesenvolvidos podem exercer uma poderosa influência na expansão das receitas de exportação dêstes últimos. Para tanto, basta mostrarmos a importância da tarifa efetiva mesmo no caso de uma tarifa nominal baixa sôbre o produto final.

Vamos supor:

a) uma tarifa nominal sôbre o produto final igual à média das tarifas nominais sôbre produtos finais nos países desenvolvidos, ou seja, $\mathrm{t}=12 \%$

b) Uma tarifa nominal sôbre os materiais igual a um nível bastante comum ao existente para matérias-primas nos países desenvolvidos, ou seja, $\mathrm{q}=2 \%$

c) $\mathrm{Pj}_{1}=\$ 1,00$

$\mathrm{Pi}_{1}-0,50$ 
A tarifa efetiva será

$$
f=\frac{t-q r}{1-r}=\frac{0,12(0,02 \times 0,50)}{0,50}=\frac{0,12-0,01}{0,50}=\frac{0,11}{0,50}=22 \%
$$

Portanto, neste caso, a tarifa efetiva de $22 \%$ é bem maior do que a tarifa nominal de apenas $12 \%$.

Suponhamos agora que uma preferência de $50 \%$ seja dada sòmente a alguns países. A tarifa nominal sôbre o produto final passa a ser $\mathrm{t}=6 \%$. A tarifa efetiva será:

$$
\mathrm{f}=\frac{0,06-0,01}{0,50}=\frac{0,05}{0,50}=10 \%
$$

Os países aos quais foi dada a vantagem tarifária levam agora uma vantagem de $12 \%$ em relação aos países aos quais não foi dada a preferência; e, em relação aos produtores nacionais, os países aos quais foi dada a preferência levam uma desvantagem de apenas $10 \%$, em vez de $22 \%$, como anteriormente.

Alternativamente, suponhamos que seja dada uma preferência de $100 \%$ a alguns países. A tarifa nominal será então $t=0$, e continuamos com $q=0,02$. A tarifa efetiva será:

$\mathrm{f}=\frac{\mathrm{t}-\mathrm{qr}}{1-\mathrm{r}}=\frac{\mathrm{O}-(0,02 \times 0,50)}{0,50}=\frac{-0,01}{0,50}=-0,02=-2 \%$

Portanto, uma preferência de $100 \%$ a alguns produtores estrangeiros irá impor uma desvantagem de custo de $2 \%$ aos produtores nacionais. Isto ocorre em razão do custo mais alto da matéria-prima impôsto ao produtor nacional, sem que haja alguma compensação a êste, através de tarifa sôbre produto final. Neste caso, é de $22 \%$ a margem de preferência tarifária, em relação ao outro produtor de um país que não obteve a preferência.

Um estudo realizado por G. L. REUBeR ${ }^{7}$ concluiu que a eliminação de tarifas aplicáveis aos países subdesenvolvidos, combinada com a ma-

7 Reuber, G. L. Canada's Interest in the Trade Problems of the Less Developed Countries, Montreal, The Canadian T. C. of the P.P.A.C., maio de 1964, p. 23-27. Citado por Johnson, H. J., op. cit., p. 170. 
nutenção de tarifas aplicáveis aos países desenvolvidos, proporcionaria grandes benefícios aos países subdesenvolvidos. Usando uma tarifa média estimada de $12 \%$ nos países desenvolvidos e uma suposta elasticidade de 2 , êle conclui que esta estratégia aumentaria as exportações dos países subdesenvolvidos dos bens em questão (manufaturas, correspondendo a $5 \%$ do total de suas exportações) de $25 \%$, ou aproximadamente US\$600 milhões por ano.

Eduardo Matarazzo Suplicy

A Academia Internacional de Administração foi criada como parte integrante do $\mathrm{CIOS}$ - Conseil International pour l'Organisation Scientifique — em 1958. Sua finalidade é produzir um impacto criador intelectual e estimular tôdas as organizações e indivíduos interessados no movimento de administração, e agir como um organismo de pesquisa fundamental nas teorias, filosofias, terminologias e normas da arte e da ciência da administração, atualmente em evolução, e seus princípios básicos. Os membros da Academia são eleitos pela Junta de Diretores do CIOS, de acôrdo com indicação feita pela Junta Administrativa da própria Academia. 